\title{
Cidades Médias e a disseminação do Covid-19 na Bahia
}

\author{
Medium Cities and the spread of Covid-19 in Bahia
}

\author{
Rita de Cássia Oliveira Lima Alves' \\ Cristiana Lima Oliveira ${ }^{2}$ \\ Josenaldo de Souza Alves ${ }^{3}$ \\ Layze Santos Soarest
}

\begin{abstract}
Resumo: Reconhecer a influência das cidades médias no desenvolvimento de uma região requer, especialmente em períodos de crise, a identificação da realidade local, contextualizada na rede urbana na qual as mesmas se inserem. O presente estudo tem como propósito, assim, contribuir para uma reflexão preliminar sobre o papel das cidades médias brasileiras, especificamente aquelas localizadas no território baiano, quanto às suas capacidades de atuação frente ao atual momento de pandemia que se instala no país neste ano de 2020.Como resultado das análises, verifica-se que, para o enfrentamento de tal condição, é fundamental que as condições sociais e econômicas relacionados a infraestrutura social e urbana ainda necessitem de aprimoramento. Assim, há desafios pontuais neste ambiente, desde aqueles relacionados ao aparelhamento urbano, até aqueles referentes à melhoria da distribuição da renda e melhoria da qualificação técnica da população, dentre outros.
\end{abstract}

Palavras-chave: Cidades médias. Covid-19. Influência regional. Pandemia. Rede urbana.

Abstract: Recognizing the influence of medium-sized cities on the development of a region requires, especially in times of crisis, the identification of the local reality, contextualized in the urban network in which they are inserted. The purpose of this studyis, therefore, to contribute to a preliminar reflection on the role of Brazilian medium-sized cities, specifically those located in Bahia, regarding their capacity to act in the face of the current moment of pandemic that is installed in the country in this year of 2020. As a result of the analysis, it appears that, in order to face this condition, it is essential that the social and economic conditions related to social and urban infrastructure, still need to be improved. Thus, there are specific challenges in this environment, from those related to urban equipment, to those

\footnotetext{
${ }^{1}$ Universidade Estadual do Sudoeste da Bahia - UESB. Doutora em Geografia - UB- ES, Professora Titular, Coordenadora do Grupo de Pesquisa Cidades Médias e Redes de Empresas, rcassialimaa@gmail.com.

${ }^{2}$ Universidade Estadual do Sudoeste da Bahia - UESB. Graduanda em Administração - UESB, Membro do Grupo de Pesquisa Cidades Médias e Redes de Empresas, crislimaoliveira.br@gmail.com.

${ }^{3}$ Faculdade Independente do Nordeste- Fainor. Mestre em Ciências Contábeis - Fucap - ES, membro do Grupo de Pesquisa Cidades Médias e Redes de Empresas, josenaldodesouzaalves@gmail.com.

${ }^{4}$ Universidade Estadual do Sudoeste da Bahia - UESB. Bacharela em Direito, Grupo de Pesquisa Cidades Médias e Redes de Empresas-UESB, layzesoares@hotmail.com.
} 
related to improving income distribution and improving the technical qualification of the population, among others.

Keywords: Medium cities. Covid-19. Regional influence. Pandemic. Urban network.

\section{Introdução}

O presente trabalho tem como propósito contribuir para uma reflexão preliminar sobre o papel das cidades médias na Bahia frente à realidade de pandemia pela qual o mundo atravessa na atualidade. O processo de globalização, já instalado há algum tempo, vem provocando modificações estruturais e impondo, nas últimas décadas, novos papéis às cidades, por meio de variadas escalas urbanas. Essas, por sua vez, são determinadas pelo tamanho, densidade demográfica, além de suas funções e interações espaciais. Tal condição alerta para a compreensão sobre a consonância entre as mudanças no conteúdo e a forma que se apresenta o espaço urbano, na atualidade.

No Brasil, evidencia-se um espaço urbano mais heterogêneo, sujeito às mais variadas formas de desumanização das relações, decorrentes de um quadro histórico contínuo de desigualdades regionais e, consequentemente, sociais. Em um cenário de pandemia mundial, um alerta mais amplo sinaliza, neste momento, para, sobretudo, a necessidade de preservação de vidas, a partir dos conteúdos e papéis das cidades médias. Essas, por sua vez, se revelam em importantes instrumentos de planejamento regional, ao centralizarem os mais variados equipamentos urbanos, com vistas a promoção da melhoria das condições de vida de determinada região.

Dessa maneira, este trabalho está estruturado de forma a realizar uma breve reflexão sobre a dinâmica conceitual das redes urbanas e cidades médias. Em seguida, busca-se analisar a relação entre o papel das cidades médias da Bahia e a situação de pandemia, devido ao alastramento da Covid-19. Quanto à metodologia utilizada para a realização da pesquisa, trata-se de estudo qualitativo, o qual possui natureza descritivo-exploratória, ao buscar reconhecer os aspectos referentes à relação entre cidades médias e a pandemia de Covid-19. Para tanto, refletiu-se sobre os papéis das cidades médias, especificamente as três cidades médias localizadas na Bahia - Feira de Santana, Eixo Ilhéus-Itabuna e Vitória da Conquista, tendo em vista que suas dinâmicas urbanas são condições essenciais à implementação de equipamentos capazes de atender à população da sua região. Ao final, tece-se as considerações finais, indicando algumas sugestões e estratégias para pesquisas futuras. 


\section{A rede urbana e as cidades médias}

Considerando as diversas características da rede urbana brasileira, compreende-se que, dada as peculiaridades sociais e econômicas deste país, a mesma é vista a partir de variados padrões e diferenças de regionalização. Nas palavras de Correia (1997), rede urbana constituise no conjunto de centros urbanos funcionalmente articulados entre si. Cabe, portanto, distinguir os papéis desempenhados pelas cidades em suas respectivas redes urbanas, identificando suas funções urbanas integradas às suas interações espaciais.

Para tanto, é essencial compreender o que vem a ser cidade, sob a perspectiva dos diversos estudiosos. Santos (1993), crítico estudioso sobre o tema, já afirmava que:

[...] é muito antigo o problema de definir corretamente o que seja uma cidade. Embora esta questão também seja analisada por sociólogos e economistas, o ponto de vista que nos interessa aqui é o geográfico, pois a cidade constitui uma forma particular de organização do espaço, uma paisagem, e, por outro lado, preside as relações de um espaço maior, sem seu derredor, que é a sua zona de influência (SANTOS, 1993, p. 131).

O espaço de uma cidade constitui-se, portanto, em um primeiro momento, no conjunto de diferentes usos da terra justapostos entre si. Este complexo conjunto de usos da terra é, na verdade, a organização espacial da cidade ou, simplesmente, espaço urbano, associado aos seus equipamentos urbanos. Dessa forma, de acordo com Oliveira Jr (2008), o espaço urbano, visto enquanto materialização dos processos socioespaciais, apresenta-se ativo, na medida em que o modo de produção capitalista impele transformações à sociedade. O espaço urbano, enquanto cidade, não é um espaço neutro. Este comporta forças de sobrevivência e de evolução, por meio da sua capacidade de produção e certa disposição de ação e reação diante das suas necessidades.

Quanto às cidades médias, uma das mais significativas discussões relaciona-se à capacidade de intermediação que este perfil de cidade poderia desenvolver com as pequenas e grandes cidades, em função do seu papel integrador e intermediador. Na década de 1930, Christaller, W. (1966) buscou explicar, por meio da Teoria dos Lugares Centrais, a centralidade do espaço organizado em torno de um núcleo urbano principal, denominado lugar central. A região complementar, ou entorno, possuiria uma relação de co-dependência com o núcleo principal, por este constituir-se no lócus ofertante de bens e serviços, sendo genuinamente urbanos. Quanto maior a centralidade, maior o seu entorno, ou seja, quanto 
maior a complexidade do serviço oferecido, maior a área atendida por esse centro, devendo ser, também, densamente povoado com presença de atividades comerciais e industriais.

Ao longo do tempo, outros fatores foram considerados na definição de cidades médias. Mais recentemente, há um uso crescente do adjetivo "intermédia” para classificar esta categoria de cidades. Segundo Bellet Sanfeliu e Llop Torné (2003):

La delimitación del objeto de estúdio con rígidos criterios de cantidad resultaria totalmente infructuosa. Las ciudades se consideran intemedias no solo con arreglo a tallas demográficas y dimensiones determinadas (coherentes con su contexto geográfico), sino, sobre todo, com relación a las funciones que desarrollan: el papel de mediación em los flujos (bienes, información, innovación, administración, etc.) entre los territorios rurales y urbanos de su área de influencia y los otros centros o áreas, más o menos alejados (BELLET SANFELIU; LLOP TORNÉ, 2003, p. 2).

Para as autoras, outras dimensões a serem consideradas são a intermediação dos fluxos de bens, informações e inovação. Outrossim, mesmo a terminologia "cidades médias" induz ao caráter de rigidez, sugerindo-se, inclusive, a sua substituição pela terminologia "intermedias". Fato é que, ante a complexidade de tal configuração, é imperativo novos enfoques para as emergentes questões da urbanização. A educação, saúde, segurança, habitação, lazer, enfim, a qualidade de vida de sua população dependem de estratégias condizentes com o contexto em que as cidades vivenciam atualmente, ao se considerar o papel que a cidade média pode promover, segundo Fournier (1999):

Como centros que contribuem ou podem contribuir para um processo de urbanização mundial mais sustentável e territorialmente mais equilibrado; Como centros que estabelecem relações mais diretas e equilibradas na sua área de influência; Como um tipo de assentamento humano, que pode oferecer maior qualidade de vida à população residente, em função da sua escala urbana; Como centros que podem permitir uma maior participação cidadã no governo da cidade e seus assuntos (FOURNIER, 1999, p. 9).

Revela-se importante, então, o papel e a função que este perfil de cidade exerce, além dos fluxos estabelecidos na e além da sua região de influência. Essencial ainda que estas cidades constituam-se em centros disponibilizadores de bens e serviços relativamente especializados, destinando-os à população local edo seu entorno.

Neste contexto, insere-se o estudo produzido pelo IBGE, em 2007, sobre Regiões de Influência das cidades - REGIC, que analisa a hierarquia, o papel e os fluxos entre as cidades. O objetivo foi estudar e atualizar a análise da rede urbana do Brasil, além de subsidiar o 
planejamento estatal e as decisões relacionadas às atividades econômicas de produção, consumo privado e coletivo. Procurou o estudo ainda fomentar o conbecimento das relações sociais vigentes e dos padrões espaciais que delas emergem, considerando-se os seus centros urbanos.

Considerando essa realidade, Oliveira Jr e Soares (2010) elaborou importante proposta metodológica para o estudo das cidades médias. Assim, inspirou o autor a proposta metodológica do Programa Ciudades Intermedias y Urbanización Mundial,desenvolvido pela União Internacional dos Arquitetos (UIA), em parceria com o Ajuntament de Lleid, Projeto Monitoreo de Ciudades Intermedias, publicado no ano de 2003, sob o título Intermediación urbana: ciudades de América Latina em su entorno.

Quanto às cidades médias no Brasil, a configuração destas remonta a específicas reflexões sobre o processo de urbanização, considerando que tais cidades passaram a obter maior relevância no âmbito das redes urbanas, a partir da década de 1970, por meio das políticas de planejamento urbano regional. As razões advindas desta conceituação têm relação direta com a França das décadas de 1950 e 1960 quando, nesta época, emergiram debates relacionados ao desenvolvimento regional referendados na redução dos desequilíbrios provocados pelo aumento da concentração de pessoas nas grandes cidades. Para Costa (2002):

O Conceito de "cidade média" só surgiu, pela primeira vez, uns anos mais tarde em França, associado às políticas de desconcentração de população e atividades implementadas pelo VI Plano de Desenvolvimento Econômico e Social (19711975) (COSTA, 2002, p. 4).

Em 1970, a maioria da população urbana brasileira já se encontrava localizada junto aos grandes centros. A rede urbana era, à época, composta por duas metrópoles nacionais (Rio de Janeiro e São Paulo). De acordo com Souza (2008), havia ainda algumas metrópoles regionais, a exemplo de Belém, Salvador, Belo Horizonte e Porto Alegre. O crescimento populacional das cidades médias relacionava-se às políticas de ordenamento territorial para “desafogar" as metrópoles (áreas de forte atração para movimentos migratórios). Ademais, havia uma ampla rede de pequenas cidades, que faziam o elo entre o urbano e o rural. As cidades médias tornaram-se, assim, uma possibilidade para restringir o deslocamento de migrantes para as áreas metropolitanas, já saturadas. As políticas públicas foram, dessa forma, implementadas para reforçar o papel dessas cidades como condição de efetivação de uma rede urbana mais equilibrada. 


\section{As cidades médias na Bahia e a Covid-19}

Vivencia-se, atualmente, um quadro de dificuldades enfrentadas no mundo, reforçado pela crise instalada pela pandemia, decorrente do rápido alastramento do coronavírus, no ano de 2020. No Brasil, são 1.344.146 pessoas afetadas, conforme dados de 28 de junho de 2020 (MINISTÉRIO DA SAÚDE, 2020) e a doença avança rapidamente afetando significativamente a saúde da população. Tal condição logo impactou na necessidade de orientação da Organização Mundial de Saúde (OMS, 2020) para o combate de tal vírus, como medida essencial à preservação de vidas, uma vez que, no Brasil, são 57.629 pessoas que evoluíram a óbito. País de grande extensão territorial, o Brasil vivencia, em 2020, o desafio de abreviar, temporalmente, as distâncias físicas extremas para que o acesso à saúde seja o menos desigual possível, sobretudo frente à realidade de desigualdades regionais em que se apresenta. Ante essa realidade, nas palavras de Alves (2019), esta situação se agrava ao se considerar que:

Dadas as dificuldades estruturais, as áreas afastadas dos grandes centros do país, encontram-se em desvantagem. Trata-se de regiões, cujo declínio social e econômico, geram baixa proporcionalidade de médicos e equipamentos de saúde, sobretudo a pública (ALVES, 2019, p. 118).

Diante de tal realidade e com a necessidade contínua de planejamento da saúde coletiva, as cidades médias enfrentam o desafio de atender para além da sua população urbana. Portanto, esse perfil de cidade é, com frequência, considerado como fundamental nó em suas redes geográficas. Na Bahia, de acordo com Secretaria da Saúde do Estado da Bahia (SESAB, 2020), os casos confirmados de Covid-19, até 28 de junho de 2020, são de 68.495 casos, totalizando 1.748 óbitos ocorridos em 2020.Quanto às cidades médias da Bahia, a exemplo de Feira de Santana, Vitória da Conquista e eixo Ilhéus-Itabuna, estas, além de populosas, também são importantes centros regionais, absorvendo, assim, as demandas dos casos mais graves e, ainda, podendo assumir o risco de grandes disseminadoras do vírus em evidência.

Feira de Santana, segunda cidade em população da Bahia, desempenha importante papel no contexto regional, realizando a intermediação entre os municípios circunvizinhos. Segundo o Instituto Brasileiro de Geografia e Estatística (IBGE, 2020), o município possui uma população, em 2019, de 614.872 pessoas. De acordo com Freitas (2010 apud SANTOS; SILVA; ALVES, 2013, p. 4): 
Ao analisar o processo de urbanização de Feira de Santana, observa-se que, desde o final do século XIX, sua posição intermediária é decorrente do desenvolvimento das atividades produtivas, especialmente da pecuária; porém, tomando-se como parâmetro o tamanho demográfico, assume a condição de cidade média na década de 1970, quando alcança população urbana superior a 100 mil habitantes (FREITAS, 2010 apud SANTOS; SILVA; ALVES, 2013, p. 4).

Feira de Santana oferta serviços e comércio de bens diversificados, suprindo, dessa forma, as necessidades da população das cidades circunvizinhas. No âmbito da saúde, de acordo com a SESAB (2020), Feira de Santana dispõe de 140 leitos para atendimento exclusivo a pacientes infectados pela Covid-19. Os casos confirmados no município, até 28 de junho de 2020, são de 3.072. Outros quarenta e seis casos evoluíram a óbito.

Vitória da Conquista teve o seu crescimento urbano intensificado na década de 1940, por meio da expansão urbana do município em direção às principais rodovias federais e estaduais, constituindo-se, assim, em um dos seus principais vetores de crescimento urbano. A década de 1970 foi marcada pelo crescimento da malha urbana, estimulado pela economia cafeeira e seus reflexos no comércio e serviços. A integração com outras regiões possibilitou a consolidação de Vitória da Conquista como um centro comercial regional.

Histórica e geograficamente, Vitória da Conquista possui a vantagem de beneficiarse com a condição de localizar-se em um entreposto comercial e de serviços que influencia economicamente cidades da Região Sudoeste da Bahia, inclusive aquelas também localizadas no norte-nordeste de Minas Gerais. Esse traçado peculiar de entroncamento importa para a dinâmica do seu espaço urbano, especialmente aquele relacionado ao comércio, considerando que, o que se verifica é um crescimento da cidade em direção das rodovias. Nesta condição, Vitória da Conquista, de acordo com a SEI (2010), com mais de 300.000 habitantes (IBGE, 2020), concentra $85 \%$ da sua população urbana e pode ser considerada como um dos centros baianos com maior capacidade de exercer a função de polo regional.

Quanto ao seu sistema de saúde, Vitória da Conquista, que possui 341.697 mil habitantes (IBGE, 2019), tem demonstrado fragilidades e contradições em suas políticas públicas. Nesta realidade, a cidade, ainda assim, possui equipamentos urbanos relacionados à saúde, além de hospitais, prontos-socorros e clínicas especializadas. Entretanto, a falta de médicos tem sido apontada como um dos grandes problemas nesta cidade média. Reconhecese, no entanto, que o processo de municipalização/descentralização do seu sistema de saúde, desde a década de 1990, revelou contornos e formas mais acertadas de gerir esse importante recurso para a sua região de influência. Nesse sentido, Ferraz (2009) afirma que: 
Vitória da Conquista construiu sua história no setor de saúde, engendrada por um conjunto de decisões, tanto individuais quanto de grupos, da iniciativa privada e pública, sofrendo pressões externas e internas, além da influência do processo de incorporação tecnológica (FERRAZ, 2009, p. 202).

Reconhece-se, portanto, que, não obstante todas as dificuldades e consequente discutível qualidade dos serviços de saúde, a atual realidade é bem diferente daquela de décadas passadas. Verifica-se, no entanto, que, para atender as demandas de tamanha proporção, pacientes são acolhidos, muito embora a disponibilidade de vagas nem sempre seja suficiente para contemplar tal realidade. Ratificando o exposto, Alves (2019) afirma que:

É, inclusive, comum, o deslocamento de moradores das cidades circunvizinhas a Vitória da Conquista, em busca de serviços de média ou alta complexidade, aos quais não teriam acesso em seus municípios de origem. Mas, ao se dirigirem às unidades de saúde desta cidade média, encontram dificuldades de atendimento (ALVES, 2019, p.121).

Ainda assim, conduzidos pela necessidade desse serviço, sobretudo no momento atual, moradores de outros municípios menores se deslocam para este espaço, gerando um fluxo contínuo de pacientes a Vitória da Conquista. Quanto aos dados relacionados à Covid19, em Vitória da Conquista, de acordo com a SESAB (2020), atualmente, há 675 casos confirmados, além de quinze óbitos até 28 de junho de 2020. O município conta com 50 leitos de UTI reservados à Covid-19. Destes, há uma taxa de ocupação de 59\%. Ainda de acordo com a SESAB (2020), os hospitais disponibilizados para esse fim são, prioritariamente, o Hospital do Estado, além do Hospital das Clínicas de Conquista. Ademais, as demais unidades hospitalares da cidade, também têm realizado esse atendimento.

Quanto ao eixo Itabuna e Ilhéus, de acordo com o último censo demográfico (IBGE,2020), os municípios possuem 204.667 e 184.236 habitantes respectivamente. Quanto à sua configuração urbano-regional, três características lhes são distintivas para que se exerça tal influência. A primeira refere-se à existência de grande número de cidades em pequena extensão territorial. Já a segunda refere-se à existência de aglomeração urbana constituída pelas cidades de Ilhéus e Itabuna, distantes apenas 31,1 quilômetros uma da outra. São cidades que apresentam relativa divisão e complementaridade de funções e atividades. Por fim, há dois "anéis urbanos", subsistemas urbanos gradativamente menos complexos, configurados segundo a distância de Itabuna/Ilhéus, conforme Secretaria do Desenvolvimento Urbano (SEDUR, 2019). 
No âmbito da saúde, Itabuna e Ilhéus fazem parte do mesmo núcleo regional, sendo Ilhéus a gestora municipal dos serviços de saúde. Com mais de 3.533 casos confirmados de Covid-19 até 28 de junho de 2020, além de 99 óbitos entre as duas cidades, a região enfrenta o avanço da pandemia com uma Unidade de Atendimento com 22 leitos no Centro de Convenções de Ilhéus para acolher pacientes suspeitos de infecção. Em Ilhéus, a estrutura de atendimento da região conta com dez leitos de UTI no Hospital de Ilhéus. Já Itabuna oferece dez leitos para adultos no Hospital Calixto Midlej, três leitos infantis de UTI no Hospital Manoel Novaes, além de 40 leitos clínicos, conforme SESAB (2020).

Compreendendo ser fundamental a contenção da pandemia de Covid-19, a partir da articulação e integração destas cidades nas diferentes regiões do estado, tece-se, a seguir, as seguintes análises. Para o enfrentamento da pandemia gerada pela Covid-19, é fundamental que as condições sociais e econômicas relacionados à infraestrutura social e urbana, além de maior conscientização destas cidades médias, ainda necessitem de aprimoramento. Os casos de contaminação e óbitos já fazem parte de uma realidade, a qual tende a crescer nos próximos meses, caso medidas mais drásticas não sejam adotadas.

As cidades médias apresentam maior risco para propagação espacial da doença, exigindo estratégias para reduzir o número de infecções. As desigualdades sociais constituem-se em grande preocupação frente ao agravamento da doença. Assim, há desafios pontuais neste ambiente, desde o isolamento social, aparelhamento urbano, melhoria da distribuição da renda, melhoria da qualificação técnica da população, ampliação dos equipamentos urbanos e maior conscientização da população, dentre outros. Tal condição urge, sobretudo, pelo fato de a Bahia localizar-se no Nordeste, uma das mais pobres regiões do país.

\section{Considerações finais}

Considerando o objetivo deste estudo, que é refletir, preliminarmente, sobre o papel das cidades médias brasileiras, especificamente aquelas localizadas no território baiano, quanto às suas capacidades de atuação frente ao atual momento da pandemia de Covid-19, que se instala no país, neste ano de 2020, algumas considerações são necessárias.

Não há como negar a urgência em se enfrentar uma série de desafios, considerando a influência regional das cidades médias. Verifica-se, portanto, a iminente necessidade de estratégias mais pontuais para as demandas da saúde, cuja finalidade deve responder às 
necessidades reais da população local e do seu entorno com vistas a combater, de forma mais efetiva, a Covid-19. Alerta-se para a necessidade de ações de prevenção e controle da doença. Fundamental torna-se, ainda, o apoio e participação ativa das instituições regionais, a exemplo de Associações de Municípios e Consórcios Intermunicipais. Por fim, há que se ter atenção especial às subnotificações decorrentes da insuficiência de testes.

Compreende-se, por fim, que esta foi uma das tantas possibilidades de estudos acerca do tema, os quais geraram os resultados apresentados. Outras pesquisas podem ser exploradas, o que pode resultar em análises diferenciadas. Trata-se, portanto, de um campo ainda aberto a muitos estudos e aprofundamento de pesquisa.

\section{Referências}

ALVES, R. de C. O. L. Do uno ao múltiplo: desafios e perspectivas de uma cidade média. Curitiba: CRV, 2019.

BELLET SANFELIU, Carmen; LLOP TORNÉ, Josep Maria. Miradas a otrosespacios urbanos: las ciudades intermedias. In: Catedra UNESCO UdL - Ciudades intermedias urbanización y desarrollo. 2003. Disponível em http://www.ceut.udl.cat/wpcontent/uploads/Miradas-a-otros-espacios-urbanos-las-ciudades-intermedias.pdf. Acesso em 18 de junho 2020 .

COREIA, R. L. Trajetórias Geográficas. Rio de Janeiro: Bertrand Brasil, 1997.

COSTA, Eduarda Marques da.Cidades Médias:contributos para a sua definição. Finisterra, Lisboa, v. XXXVII, n, 74, p. 121-128, 2002.

CHRISTALLER, Walter. Central Places in Southern Germany.Tradução de Carlisle W. Baskin. New Jersey: Prentice-Hall, 1966.Título original: DienZentralenOrte in süddeutschland.

FERRAZ, Ana Emília de Quadros. O espaço em movimento: o desvelar da rede nos processos sociotécnicos do sistema de saúde de Vitória da Conquista Bahia. 2009. 254 f. Tese (Doutorado em Geografia) - Universidade Federal de Sergipe, São Cristóvão, 2009.

FOURNIER, Francine. Ciudades Intermedias Y UrbanizaciónMundial. Lleiga, Espanha:Ajuntament de Lleida/UNESCO/UIA/Ministerios de Asuntos Exteriores. Direccion: Joseph M. LiopTorné. 1999.

INSTITUTO BRASILEIRO DE GEOGRAFIA E ESTATÍSTICA (IBGE). Indicadores Sociais Municipais: Uma análise dos Resultados do Universo do Censo Demográfico. 2010. Disponível em: 
<http://www.ibge.gov.br/home/estatistica/populacao/censo2010/indicadores_sociais_mun ici ais/indicadores_sociais_municipais.pdf>. Acesso em 15 junho 2020.

INSTITUTO BRASILEIRO DE GEOGRAFIA E ESTATÍSTICA - IBGE. Indicadores sociais municipais: Uma análise dos Resultados do Universo do Censo Demográfico. 2010. Disponível em:<http://www.ibge.gov.br/home/estatistica/populacao/censo2010/indicadores_sociais_ municipais/indicadores_sociais_municipais.pdf. Acesso em 20 de junho de 2020.

MINISTÉRIO DA SAÚDE. Boletim Epidemiológico Especial: Doença pelo Coronavirus COVID- 19. 2020. Disponível em: http://saude.gov.br/images/pdf/2020/July/01/Boletim-epidemiologico-COVID-20-3.pdf Acesso em 28 de junho de 2020.

OLIVEIRA JÚNIOR, Gilberto Alves de. Novas expressões de centralidade e (re)produção do espaço urbano em cidades médias: o Jequitibá Plaza Shopping em Itabuna-BA. 2008. 449 f. Dissertação (Mestrado em Geografia) - Universidade de Brasília, Brasília, 2008.

OLIVEIRA, Hélio C. M.; SOARES, Beatriz Ribeiro. Contribuições do Projeto Monitoreo de Ciudades Intermedias dos estudos das Cidades Médias:apontamentos metodológicos.

Universidade Estadual do Rio de Janeiro. Geo UERJ, Rio de Janeiro, a. 12, nº. 21, v. 2, $2^{\circ}$ semestre de 2010. Disponível em: http:/ /www.e-

publicacoes.uerj.br/index.php/geouerj/article/view/1486. Acesso em 10 de junho de 2020.

ORGANIZAÇÃO MUNDIAL DA SAÚDE (OMS). Modos de transmissão do vírus causador do COVID-19: implicações para as recomendações de precaução do IPC. 2020. Disponível em: https://www.who.int/news-room/commentaries/detail/modes-oftransmission-of-virus-causing-covid-19-implications-for-ipc-precaution-recommendations. Acesso em 18 de junho de 2020.

REGIC. Regiões de Influência das Cidades. Rio de Janeiro: IBGE, 2007. Disponível em: https://biblioteca.ibge.gov.br/visualizacao/livros/liv40677.pdf Acesso em: 15 junho 2020.

SANTOS; SILVA; ALVES. A Cidade de Feira de Santana-BA: Uma Nova (RE) Configuração Espacial Proporcionada a Partir da Expansão Comercial. In: COLÓQUIO BAHIANO TEMPOS, ESPAÇOS E REPRESENTAÇÕES - ABORDAGENS GEOGRÁFICAS E HISTÓRICAS, 1., 2013. Anais...Vitória da Conquista: UESB,2013. Disponível em: <http://anais.uesb.br/index.php/coloquiobaiano/issue/current $>$. Acesso em: 23 de junho de 2020.

SANTOS, Milton. A Urbanização Brasileira.São Paulo:Editora da Universidade de São Paulo, 1993. 
SECRETARIA DE DESENVOLVIMENTO URBANO (SEDUR). Cenário Atual do Litoral Sul: Desenvolvimento Urbano Regional. 2014. Disponível em: < www.sedur.ba.gov.br>. Acesso em: $2 \mathrm{O}$ de junho de 2020.

SECRETARIA DE SAÚDE DO ESTADO DA BAHIA (SESAB) Boletim Epidemiológico Covid-19 n. ${ }^{9} 96.2020$. Disponível em: $<$ http://www.saude.ba.gov.br/ $\geq$. Acesso em: 28 de junho de 2020.

SOUZA, Eder Júnior Cruz e. Políticas Territoriais do Estado da Bahia: regionalização e Planejamento. 2008. 158f. Dissertação (Mestrado em Geografia Econômica) - UFBA. Salvador.

SUPERINTENDÊNCIA DE ESTUDOS ECONÔMICOS E SOCIAIS DA BAHIA (SEI). Pesquisa Dinâmica Urbana dos Estados. Salvador: SEI, 2010. Disponível em: http://www.sei.ba.gov.br. Acesso em: 15 de junho de 2020. 